\title{
Cholesterol induce oligomerization of Vibrio vulnificus cytolysin specifically
}

\author{
Byeong-Soo $\mathrm{Kim}^{1,2}$ and Jong-Suk Kim ${ }^{1,3}$ \\ ${ }^{1}$ Department of Biochemistry, Institute of Cardiovascular Research, \\ Chonbuk National University Medical School, Chonju 561-756, \\ Korea \\ ${ }^{2}$ Present address: Department of Clinical Pathology, Sohae Col- \\ lege, Kunsan 573-717, Korea \\ ${ }^{3}$ Corresponding author: Tel, +82-63-270-3085; \\ Fax, +82-63-274-9833; Email, jsukim @moak.chonbuk.ac.kr
}

Accepted 10 July 2002

Abbreviation: VVC, Vibrio vulnificus cytolysin; HU, Hemolytic Unit

\begin{abstract}
Vibrio vulnificus cytolysin (VVC) has been implicated as one of the important virulence determinants of $V$. vulnificus that causes serious septicemia and wound infection. An attempt was made to investigate that VVC could act as a ligand which stimulates intracellular signaling systems. Cholesterol dose-dependently blocked VVC hemolytic activity through oligomerization of cytolysin. Among cholesterol derivatives including 7-dehydrocholesterol, cholesteryl esters, deoxycholate, and cholestane tested, only 7dehydrocholesterol induced oligomerization as well as inactivation of VVC. These results show that oligomerization of VVC is completely dependent on three-dimensional structure of cholesterol where specific interaction of cholesterol at oligomerization sites of VVC is very selective. These findings support the idea that cholesterol which constitute many of cellular plasma membrane could be a receptor of VVC on plasma membrane of target cells.
\end{abstract}

Keywords: Vibrio, bacterial toxins, cholesterol, cholesterol esters

\section{Introduction}

The halophilic bacterium Vibrio vulnificus is known to be a life-threatening pathogen that causes septicemia and serious wound infection in human. $V$. vulnificus infection is characterized by a high fatality rate of $70 \%$ and the primary attack against people who are immunocom-promised or have underlying diseases such as liver cirrhosis or hemochromatosis (Hollis et al., 1976; Blake et al., 1979; Park et al., 1991; Oliver et al., 1995). A variety of factors, including an extracellular cytolysin (Gray and Kreger, 1985), an elastolytic protease (Miyoshi et al., 1992), and resistance to phagocytosis (Yoshida et al., 1985) have all been implicated as possible virulence determinants for $V$. vulnificus septicemia in animal models. Kreger and Lockwood (1981) demonstrated that $V$. vulnificus cytolysin (VVC) showed hemolytic and lethal activity, and acted as vascular permeability factor. Although a definitive role of VVC in $V$. vulnificus infection is controversial (Oliver et al., 1986; Wright and Morris, 1991; Fan et al., 2001), VVC has still been focused because of its pore-forming nature.

VVC shows a high affinity to mammalian cell membranes, indicating that it has a broad spectrum of cytotoxicity against a variety of cells including erythrocytes, neutrophils, mast cells, endothelial cells, and macrophages (Kreger and Lockwood, 1981; Yamanaka et al., 1990; Kim et al., 1993; Park et al., 1994; Chae et al., 1996; Kim, 1997; Kim et al., 1998; Kwon et al., 2001; Kang et al., 2002). Furthermore, recent data demonstrated that VVC induce mammalian cell activation through production of intracellular signaling molecules such as hydrogen peroxide $\left(\mathrm{H}_{2} \mathrm{O}_{2}\right)$ or nitric oxide (NO) (Kwon et al., 2001; Kang et al., 2002). These reports supported that VVC could act as a ligand which stimulates intracellular signaling systems. With respect to the understanding VVC mediated signal transduction and toxic mechanism, it will be of great interest to identify a membrane receptor of VVC.

It has been known that the lysis of erythrocytes caused by VVC is colloid-osmotic in nature and that VVC, after binding to the erythrocyte membrane, oligomerize to form small pores in the membrane resulting in cell lysis (Kim et al., 1993). In addition, cholesterol inactivates VVC by converting active monomer cytolysin into inactive oligomer, suggesting that the cytolysin lyses erythrocytes through the formation of small pores on erythrocyte membrane by cholesterol-mediated oligomerization of the cytolysin (Kim et al., 1993). These results indicate that cholesterol might be a possible receptor for VVC on mammalian cells.

The aim of this study was to investigate the specificity of VVC binding to cholesterol and to propose that cholesterol could be a possible receptor for VVC. This paper shows that VVC recognize only 7dehydrocholesterol among cholesterol derivatives, suggesting that VVC binds cholesterol with defined structural specificity. 


\section{Materials and Methods}

\section{Materials}

Dulbecco's phosphate buffered saline, BSA, cholesterol derivatives, and DEAE cellulose were purchased from Sigma. (St. Louis. MO). Dulbeccos modified Eagles medium (DMEM), fetal bovine serum (FBS), and heart infusion broth were purchased from Gibco Laboratories (Grand Island, NY). Cytotoxicity detection kit of LDH was purchased from Boehringer Mannheim (Mannheim, Germany). All other reagents were of the highest purity grade available.

\section{Bacterial strain and culture}

A virulent strain of $V$. vulnificus E4125 was kindly supplied by Dr. M. H. Kothary (Department of Microbiology, Virulence Assessment Branch, Center for Food Safety and Applied Nutrition, Food and Drug Administration, Washington D.C.). The strain was cultured in the heart infusion diffusate broth as described by Kreger et al. (1988).

\section{Assay of hemolytic activity}

The hemolytic activity of VVC against mouse erythrocytes was determined by the method of Bernheimer and Schwarz (1963). VVC was diluted with phosphate-buffered saline $\left(67 \mathrm{mM} \mathrm{Na} \mathrm{HPO}_{4}, 77 \mathrm{mM}\right.$ $\mathrm{NaCl}, \mathrm{pH} 7.4$ ) containing $1 \mathrm{mg}$ of BSA per ml (PBSBSA). One milliliter of VVC was mixed with the same volume of $0.7 \%$ mouse erythrocyte suspensions in PBSBSA. After incubation at $37^{\circ} \mathrm{C}$ for $30 \mathrm{~min}$ and brief centrifugation, $A_{545}$ of hemoglobin in the supernatant was measured. One hemolytic unit (HU) is defined as that amount which liberates half of the hemoglobin in the erythrocyte suspensions.

\section{Preparation of VVC}

VVC was purified to homogeneity from the culture supernatant by ammonium sulfate fractionation, calcium phosphate gel adsorption, quaternary methylamine anion-exchange chromatography and octyl-Sepharose CL-4B chromatography as described by $\mathrm{Kim}$ et al. (1993). VVC found to be homogenous on a SDSpolyacrylamide gel. The purified VVC had a specific hemolytic activity of $80,000 \mathrm{HU}$ per mg of protein with $30 \%$ recovery.

\section{SDS-PAGE for the detection of VVC oligomer}

The oligomer of VVC was detected by a modification of the method developed by Walev et al. (1993). Samples were prepared with the same volume of $0.5 \mathrm{M}$ Tris buffer (pH 6.8) containing 4\% SDS, $20 \%$ glycerol and $0.05 \%$ bromophenol blue at room temperature. SDSPAGE was performed in $7.5 \%$ slab gel according to
Laemmli (1970). Proteins were detected by staining with Coomassie brilliant blue R 250 .

\section{Results and Discussion}

Previous data have demonstrated that VVC is inactivated by cholesterol that might be the binding site of VVC (Kim et al., 1993). Many papers indicate that a few of bacterial toxins are also inactivated by various lipids such as phospholipids, gangliosides, and cholesterol (Takeda et al., 1975; Prigent et al., 1976; Shinoda et al., 1985). However, clear structural relationship between lipids and toxins are still unknown.

In order to determine the effect of cholesterol on hemolytic activity of VVC, VVC was incubated with

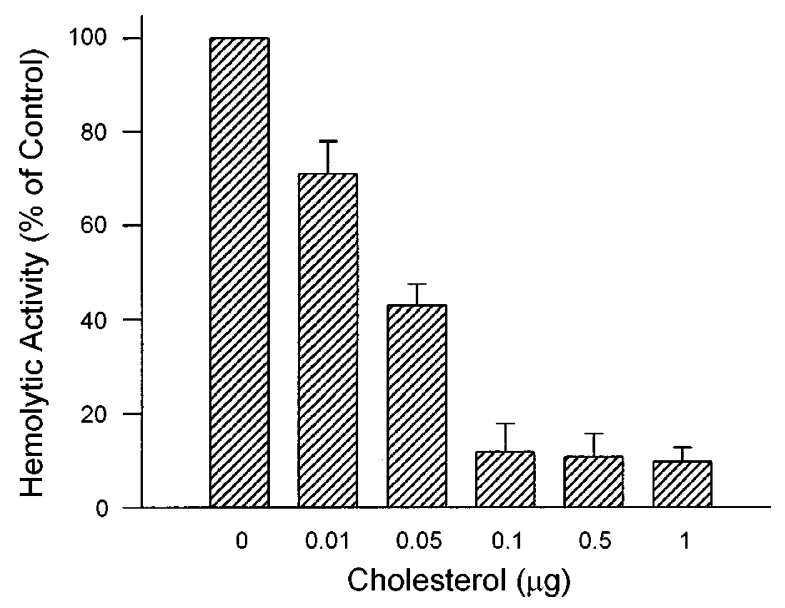

Figure 1. Effect of cholesterol on the hemolytic activity of VVC. VVC (1.0 $\mathrm{HU}$ ) was incubated with a various concentrations of cholesterol at $37^{\circ} \mathrm{C}$ for $30 \mathrm{~min}$ in a total volume of $1 \mathrm{ml}$ of phosphate-buffered saline containing 1 $\mathrm{mg}$ of BSA. The residual hemolytic activity was determined as described in the Materials and Methods. The control activity of VVC without preincubation under these conditions was arbitrarily set at $100 \%$. The each value denotes the mean $\pm \mathrm{SE}$ obtained from five experiments.

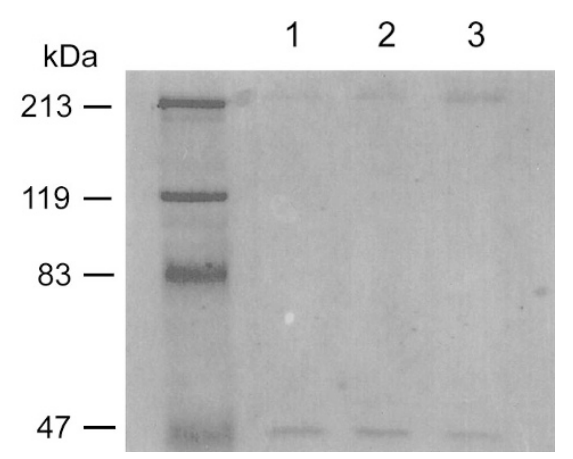

Figure 2. The detection of cholesterol-induced oligomerization of VVC by SDS-PAGE. VVC $(1 \mu \mathrm{g})$ was incubated with the indicated concentrations of cholesterol at $37^{\circ} \mathrm{C}$ for $5 \mathrm{~min}$. After separation by SDS-PAGE, proteins were stained with Coomassie brilliant blue. Lane 1, VVC alone; Lane 2, VVC with cholesterol $(0.5 \mu \mathrm{g})$; Lane 3 , VVC with cholesterol $(1 \mu \mathrm{g})$. 
<smiles>CCCC[C@H](C)C1CC[C@H]2C3=CC=C4C[C@@H](O)CCC4(C)[C@H]3CC[C@]12C</smiles>

7-Dehydrocholesterol

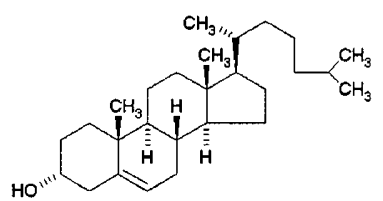

Cholesterol<smiles>CCCCCC(=O)OC1CCC2C(=CCC3C4CCC(C(C)CCCCC)C4CCC23C)C1</smiles>

Cholesteryl myristate

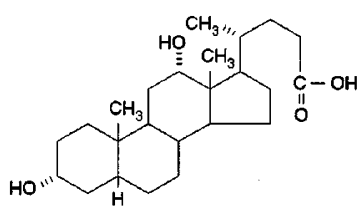

Deoxycholate<smiles>CCCCC1CCC2[C@H]3CC[C@H]4CCCCC4(C)[C@H]3CC[C@]2(C)[C@H]1C</smiles>

Choleatane

Figure 3. Cholesterol derivatives<smiles>CCCCC(=O)OC1CCC2(C)C(=CCC3C2CCC2(C)C3CCC2[C@@H](C)CCCC(C)C)C1</smiles>

Cholesteryl palmitate

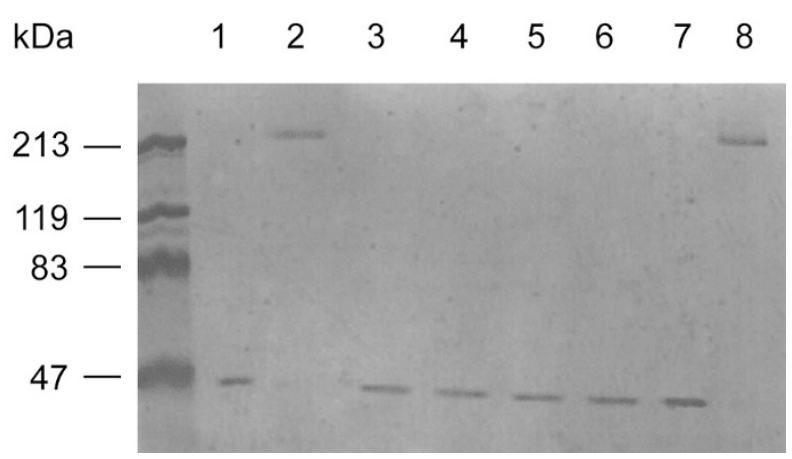

Figure 4. Effect of various lipids on the oligomerization of VVC. VVC $(1.0 \mathrm{Hu})$ was incubated with various lipids at $37^{\circ} \mathrm{C}$ for $5 \mathrm{~min}$. After separation by SDSPAGE, proteins were stained with Coomassie brilliant blue. Lane 1, VVC alone; Lane 2, VVC with cholesterol; Lane 3, VVC with cholesteryl palmitate; Lane 4, VVC with cholesteryl myristate; Lane 5, VVC with deoxycholate; Lane 6, VVC with cholestane; Lane 7, VVC with phosphatidylcholine; Lane 8, VVC with 7-dehydrocholesterol.

1976; Johnson et al., 1980). But VVC is different from those thiol-activated cytolysins because of being stable to oxygen and sulfhydryl blocking agents (Shinoda et al., 1985). This study was designed to demonstrate that VVC might uniquely interact with cholesterol molecules on plasma membranes of target mammalian cells. In order to determine whether cholesterol structure has effect on oligomerization as well as hemolytic activity of VVC or not, VVC was incubated with phosphatidylcholine or cholesterol derivatives containing a high structural similarity to cholesterol, including 7-dehydrocholesterol, cholesteryl palmitate, cholesteryl myristate, deoxycholate, and cholestane (Figure 3). Among these lipids, 7dehydrocholesterol only inactivated hemolytic activity of VVC (Table 1). Furthermore, oligomerization of VVC was also induced only by 7-dehydrocholesterol (Figure 4). These results indicate that molecular interaction between cholesterol and VVC is completely dependent on three- 
dimensional structure of cholesterol. Thus, this study strongly suggests that cholesterol serves a binding site of VVC on plasma membrane of target cells.

\section{Acknowledgments}

This paper was supported (in part) by research funds of Chonbuk National University.

\section{References}

Bernheimer AW, Schwartz LL. Isolation and composition of staphylococcal alpha toxin. J Gen Microbiol 1963;30:455-68

Blakes PA, Merson H, Weave RE, Aollis DG, Heublein PC. Disease caused by a marine Vibrio: Clinical characteristics and epidemiology. N Eng J Med 1979;300:1-5

Chae MR, KimHN, Park KH, Rho HW, Kim MA, Kim DY, Park JW, Kim HR. Species-specific hemolysis by Vibrio vulnificus cytolysin. Exp Mol Med 1996;28:95-99

Fan JJ, Shao CP, Ho YC, Yu CK, Hor LI. Isolation and characterization of a Vibrio vulnificus mutant deficient in both extracellular metalloprotease and cytolysin. Infect Immun 2001;69:5943-48

Hollis D G, Weaver R E, Baker CN, Thornberry C. Halophilic Vibrio species isolated from blood cultures. J Clin Microbiol 1976;3:425-31

Johnson MK, Geoffroy C, Alouf JE. Binding of cholesterol by sulfhydryl-activated cytolysins. Infect Immun 1980;27:97-101

Kang MK, Jhee EC, Koo BS, Yang JY, Park BH, Kim JS, Rho HW, Kim HR, Park JW. Induction of nitric oxide synthase expression by Vibrio vulnificus cytolysin. Biochem Biophys Res Commun 2002;290:1090-95

Kim HR, Rho HW, Jeong MH, Park JW, Kim JS, Park BH, Kim UH, Park SD. Hemolytic mechanism of cytolysin produced from V. vulnificus. Life Sci 1993;53:571-78

Kim JS, Chae MR, Chang K, Park KH, Rho HW, Park BH, Park JW, Kim HR. Cytotoxicity of Vibrio vulnificus cytolysin on rat peritoneal mast cells. Microbiol Immunol 1998;42:837-43

Kim JS. Cytotoxicity of Vibrio vulnificus cytolysin on pulmonary endothelial cells. Exp Mol Med 1997;29:117-21

Kook H, Lee SE, Balk YH, Chung SS, Rhee JH. V. vulnificus hemolysin dilates rat thoracic aorta by activating guanylate cyclase. Life Sci 1996;59:41-47

Kreger AS, Kothary MH, Gray LD. Cytolytic toxins of Vibrio vulnificus and Vibrio damsela. Methods Enzymol 1988;165: 176-89

Kreger AS, Lockwood D. Detection of extracellular toxin(s) produced by Vibrio vulnificus. Infect Immun 1981;33:583-90

Kwon KB, YangJY, Ryu DG, Rho HW, Kim JS, ParkJW, Kim HR, Park BH. Vibrio vulnificus cytolysin induces superoxide anion-initiated apoptotic signaling pathway in human ECV304 cells. J Biol Chem 2001;276:47518-23

Laemmli UK. Cleavage of structural proteins during the assembly of the head of bacteriophage T4. Nature 1970; 227:680-85

Miyoshi S, Hirata Y, Tomochika K, Shinoda S. Vibrio vulnificus may produce a metalloprotease causing an edematous skin lesion in vivo. FEMS Microbiol Lett 1992;121:321-25

Miyoshi S, Shinoda S. Role of the protease in the permeability enhancement by Vibrio vulnificus. Microbiol Immunol 1988; 32:1025-29

Oliver JD, Hite F, McDougald D, Andon NL, Simpson LM. Entry into, and resuscitation from, the viable but nonculturable state by Vibrio vulnificus in an estuarine environment. Appl Environ Microbiol 1995;61:2624-30

Oliver JD, Roberts DM, White VK, Dry MA, Simpson LM. Bioluminescence in a strain of the human pathogenic bacterium Vibrio vulnificus. Appl Environ Microbiol 1986; 52:1209-11

Park JW, Jang TA, Rho HW, Park BH, Kim NH, Kim HR. Inhibitory mechanism of $\mathrm{Ca}^{2+}$ on the hemolysis caused by Vibrio vulnificus cytolysin. Biochim Biophys Acta 1994; 1194:166-70

Park SD, Shon HS, Joh NJ. Vibrio vulnificus septicemia in Korea: clinical and epidemiologic findings in seventy patients. J Am Acad Dermatol 1991;24:397-403

Prigent $\mathrm{D}$, Alouf $\mathrm{T}$. Interaction of streptolysin $\mathrm{S}$ with sterols. Biochim Biophys Acta 1976;443:288-300

Shinoda S, Miyoshi S, Yamanaka H, Miyoshi-Nakahara N. Some properties of Vibrio vulnificus hemolysin. Microbiol Immunol 1985;29:583-90

Takeda Y, Hori Y, Taga S, Sakurai J, Miwatani T. Characterization of the temperature-dependent inactivating factor of the thermostable direct hemolysin in Vibrio parahaemolyticus. Infect Immun 1975;12:449-54

Walev I, Martin E, Janas D, Mohamadadeh M, Müller-Klieser W, Kunz L, Bhakdi S. Staphylococcal alpha-toxin kills human keratinocytes by permeabilizing the plasma membrane for monovalent ions. Infect Immun 1993;61:4972-79

Wright AC, Morris JG. The extracellular cytolysin of Vibrio vulnificus: Inactivation and relationship to virulence in mice. Infect. Immun. Infect Immun 1991;59:192-97

Yoshida S, Ogawa M, Mizuguchi Y. Relation of capsular materials and colony opacity to virulence of Vibrio vulnificus. Infect Immun 1985;47:446-51 